\title{
Numerical study on influence of waterway regulation project, a case study of Minjiang
}

\author{
Chunyan $\mathrm{DENG}^{1, *}$, Hua GE ${ }^{1}$ \\ ${ }^{1}$ Changjiang River Scientific Research Institute, Wuhan, Hubei, 430010, China
}

\begin{abstract}
The waterway regulation project from Longxikou junction to Hejiangmen of Yibin, Minjiang River, is an urgent need for the construction of a comprehensive transportation hub in Western Sichuan Province. It plays a positive role in promoting the social and economic development of the economic region and has significant social benefits. A two-dimensional hydrodynamic mathematical model is established to study the variation characteristics of river water level and velocity before and after the implementation of waterway regulation project. The research ideas and results can provide reference for similar projects.
\end{abstract}

\section{Introduction}

Leshan to Yibin reach, part of Minjiang, is the only channel for large equipment products in and out of Sichuan Province. It is a high-grade waterway of main trunk and tributaries, and an important part of building a national high-level water transport network. As an integral part of Minjiang navigation and power planning, the construction of waterway regulation project is in line with the relevant national and industrial planning, and in line with the State Council's opinions on speeding up the development of inland water transportation such as the Yangtze River. It is the urgent need to build a comprehensive transportation hub in Western Sichuan Province, as well as the need of social and economic development in Sichuan Province. It plays a positive role in promoting the social and economic development of economic regions.

Many scholars have studied the waterway regulation project ${ }^{[1-4]}$, aiming at the waterway obstruction problem during the dry season of the Changzhou Water Conservancy Hub to the Jieshou River section of the Xijiang Shipping Trunk Line, Liu Linxiong ${ }^{[1]}$ collect the hydrological and topographic map data to study the cause. Xiao Liminin $^{[2]}$ established a three-dimensional tidal current mathematical model and carried out a simulation study on the tidal current distribution of the east and north breakwater extension scheme of Dagukou Port area of Tianjin Port. In order to optimize the channel regulation project of this section, Ben Peng ${ }^{[3]}$ established a two-dimensional hydrodynamic mathematical model of the river channel according to the characteristics of the river section. In this paper, the waterway regulation project in Minjiang River reach is studied, and its influence on flood control and river regime is analysed through a two-dimensional mathematical model calculation, so as to provide a technical support for the implementation of the project.

\section{Study area, data and method}

\subsection{Study area and data}

Minjiang is a primary tributary of the upper reaches of the Yangtze River. The Minjiang River Basin is located in the western edge of the hinterland of Sichuan Basin, $99^{\circ} 42^{\prime}-104^{\circ} 40^{\prime} \mathrm{E}$ and $28^{\circ} 20^{\prime}-33^{\circ} 38^{\prime} \mathrm{N}$. The terrain is high in the northwest and low in the southeast, with a drainage area of $135411 \mathrm{~km} 2$, a total length of $735 \mathrm{~km}$, a natural drop of $3560 \mathrm{~m}$, an average gradient of $4.84 \%$, and an average annual flow of $3022 \mathrm{~m} 3 / \mathrm{s}$. According to the topography and channel characteristics, the main stream of Minjiang is divided into upper, middle and lower reaches with Dujiangyan and Dadu River Estuary as boundary points.

The study area is a part of the navigation section from Longxikou junction of Minjiang River to Hejiangmen of Yibin. There are four beach with navigation risks in the study area, including Ganlongzi, Longxikou, Laojunqi and Baijia (shown in Figure 1). This reach is a wide and shallow river channel with single channel and branch flow alternately. It belongs to mountainous river with rapid flow velocity, steep gradient, disordered flow pattern, large variation range of flood and dry water level, and steep rise and fall of water level in flood season. 


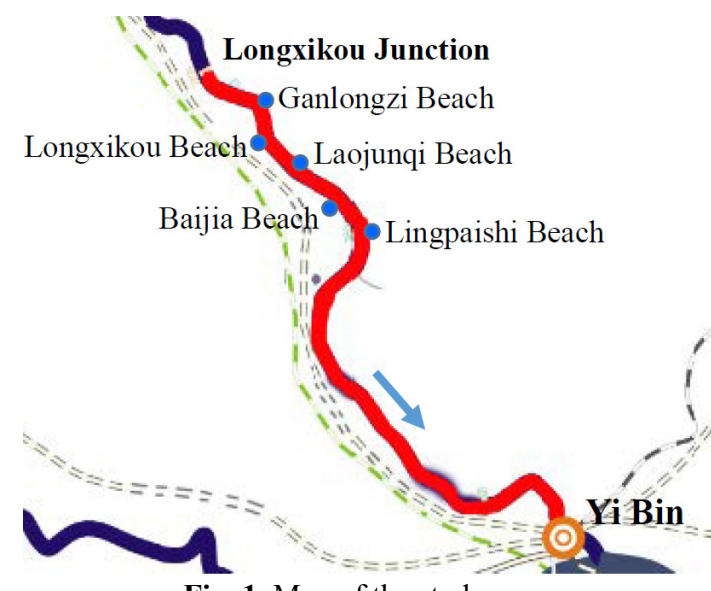

Fig. 1. Map of the study area.
This section is a wide and shallow channel with single channel and branch flow alternately, and the flow is not very concentrated, which is the fundamental reason for the insufficient beach depth. In view of the navigation obstruction in this section, the engineering measures mainly include: dam, dredging and shoal (Island) belt protect engineering (see Figure 2).

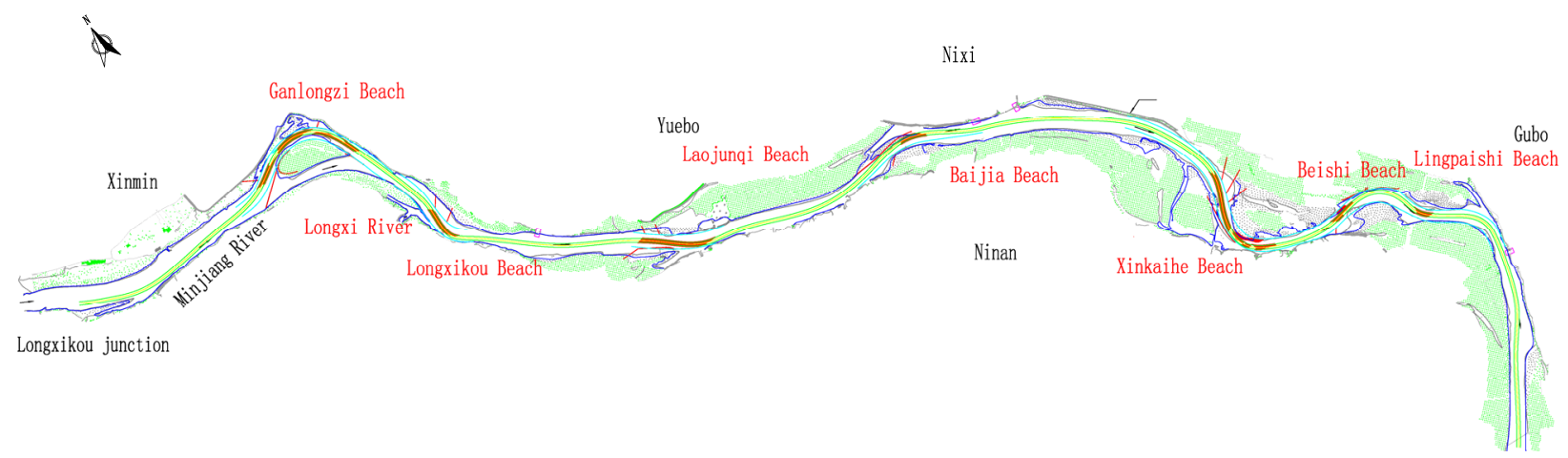

Fig. 2. Map of the proposed waterway regulation project.

\subsection{Method}

In this paper, the two-dimensional mathematical model[5] of river flow is used to calculate the flow field of the river near the proposed waterway regulation project. By calculating the changes of water level and flow velocity before and after the implementation of the regulation project, the impact of the project on flood control and river regime is evaluated. After the construction of the project, the influence of the project on the water level and velocity of the river is mainly reflected by changing the local river topography of the project. The calculation is divided into two working conditions, namely 5\% frequency flood discharge and regulation flow, as shown in Table 1.

Table 1. Boundary conditions of the calculations.

\begin{tabular}{|c|c|c|}
\hline Condition & $\begin{array}{c}\text { Flow Discharge } \\
\left(\mathbf{m}^{\mathbf{3}} / \mathbf{s}\right)\end{array}$ & $\begin{array}{c}\text { Down water } \\
\text { level (m) }\end{array}$ \\
\hline $5 \%$ frequency flood & 36200 & 292.45 \\
\hline regulation flow & 2250 & 275.25 \\
\hline
\end{tabular}

\section{Results}

\subsection{Water level changes}

Figure 3 is the contour map of water level change, and Table 2 is the statistics of maximum water level change after the project of the whole calculated river reach. It can be seen from the figure and table that the water level changes after the project are mainly concentrated in the upstream and downstream local areas of the regulation projects.

Table 2. Statistics of maximum water level change after the project.

\begin{tabular}{|c|c|c|}
\hline \multirow{2}{*}{ Condition } & \multicolumn{2}{|c|}{ Water level change (cm) } \\
\cline { 2 - 3 } & Backwater & Reduction \\
\hline $5 \%$ frequency flood & 8 & -9 \\
\hline regulation flow & 9 & -10 \\
\hline
\end{tabular}

Under the condition of regulation discharge, the maximum increase value of water level is $9 \mathrm{~cm}$, and the maximum decrease value is $10 \mathrm{~cm}$. Since the waterway regulation project is a low water structure, the project has a greater impact on the river water level and velocity under the regulation flow condition. 

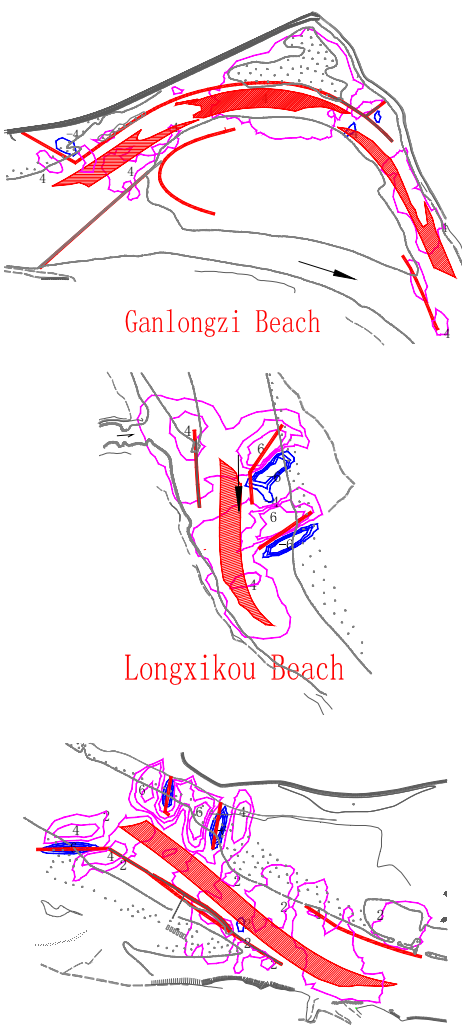

Laojunqi Beach

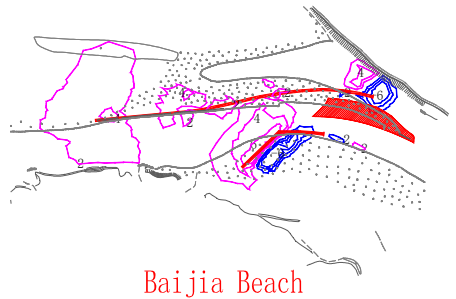

\subsection{Flow velocity changes}

Figure 4 shows the contour map of velocity changes near the proposed project, and Table 3 shows the maximum value of velocity changes and the velocity influence range after the project. It can be seen from the figure and table that the change of flow velocity after the project is mainly located in the local area of upstream and downstream of the proposed project. Due to the water blocking and backwater effect of the proposed project, the flow velocity generally decreases at the upstream or outside of the regulation structures. There is a flow velocity reduction area between and downstream of the regulation structures. And the general flow velocity increases in the river near the mainstream side and outside the regulation structure.

Under the condition of $5 \%$ frequency flood, the velocity variation is generally between $+0.44 \mathrm{~m} / \mathrm{s}$ and $0.48 \mathrm{~m} / \mathrm{s}$. And the variation range of velocity under regulation flow condition is generally $0.02 \sim 0.1 \mathrm{~m} / \mathrm{s}$. Generally, the smaller the discharge and the lower the water level, the stronger the disturbance of the regulation structure on the flow field, and the greater the impact on the flow velocity after the project.

Table 3. Maximum flow velocity change after the project.

\begin{tabular}{|c|c|c|c|c|}
\hline \multirow{2}{*}{ Beach section } & \multicolumn{2}{|c|}{$5 \%$ frequency flood } & \multicolumn{2}{c|}{ regulation flow } \\
\cline { 2 - 5 } & Increase & Decrease & Increase & Decrease \\
\hline Ganlongzi & 0.26 & 0.27 & 0.51 & 0.49 \\
\hline Longxikou & 0.22 & 0.36 & 0.47 & 0.62 \\
\hline Laojunqi & 0.44 & 0.48 & 0.59 & 0.66 \\
\hline Baijiatan & 0.25 & 0.21 & 0.46 & 0.59 \\
\hline
\end{tabular}

Fig. 3. Contour map of water level change (Ganlongzi Beach).

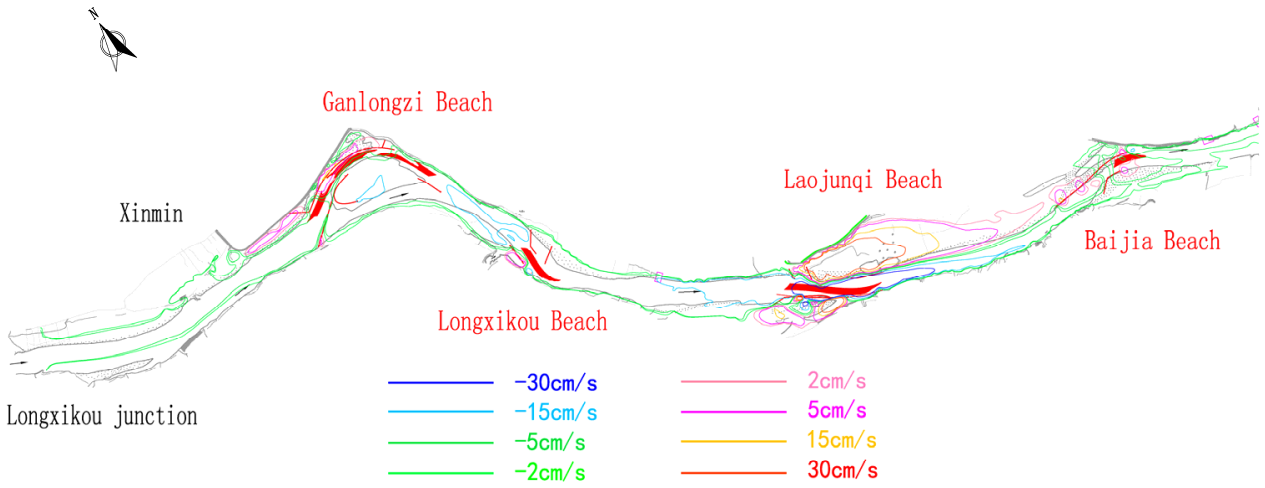

Fig. 4. Contour map of flow velocity change.

\section{Conclusions}

The results of the two-dimensional numerical simulation show that: for the dam projects, the upstream water level of the dam rises and the downstream water level decreases; for the dredging projects, the basic performance is that the water level in the upstream of the project is decreased, and the water level in the downstream of the project is increased. The variation range of velocity mainly concentrated in the upstream and downstream of the project.

\section{Acknowledgments}

This work was supported by National Key R\&D Program of China 2017YFC0405306. 


\section{References}

1. LIU Lin-xiong, LI Jun-na, HUANG Wen-hui. Analysis of channel obstruction from Changzhou water control project to Jieshou reach and its regulation measures. Port \& Waterway Engineering, 7(2020)

2. XIAO Li-min, SUN Lin-yun, SUN Bo. Numerical simulation of three-dimensional tidal current in Dagukou Port area of Tianjin Port. Port \& Waterway Engineering, 9(2020)

3. BEN Peng, LU Hai-tian, ZHANG Hui. Channel regulation of main stream of the Huaihe R iver from Linhuaigang to Lutaizi section. Port \& Waterway Engineering, 8(2020)

4. HUANG Zhi-yang, JIA Yu-shao, DING Qi. Regulation plan of the channel near the entrance of the first harbor basin in Tongzhou Bay of Nantong Port . China Harbour Engineering. 40(1) (2020)

5. GE Guo-qing, SUN Ce, GENG Zhuo. Analysis of Flow and Sediment Scouring and Silting in Daqinghe River Channel under the Influence of Regulation Project. Science Technology and Engineering, 19(27) (2020) 